\title{
Will universal access to antiretroviral therapy ever be possible? The health care worker challenge
}

\author{
André R Maddison MSc (candidate) ${ }^{1}$, Walter F Schlech III MD²
}

AR Maddison, WF Schlech. Will universal access to antiretroviral therapy ever be possible? The health care worker challenge. Can J Infect Dis Med Microbiol 2010;21(1):e64-e69

The United Nations millennium development goal of providing universal access to antiretroviral therapy (ART) for patients living with HIV/AIDS by 2010 is unachievable. Currently, four million people are receiving ART, of an estimated 13.7 million who need it. A major challenge to achieving this goal is the shortage of health care workers in low-income and low-resource areas of the world. Sub-Saharan African countries have $68 \%$ of the world's burden of illness from AIDS, yet have only $3 \%$ of health care workers worldwide. The shortage of health care providers is primarily caused by a national and international 'brain drain,' poor distribution of health care workers within countries, and health care worker burnout.

Even though the millennium development goal to provide universal access to ART will not be met by 2010, it is imperative to continue to build on the momentum created by these humanitarian goals. The present literature review was written with the purpose of attracting research and policy attention toward evidence from small-scale projects in sub-Saharan Africa, which have been successful at increasing access to ART. Specifically, a primary-care model of ART delivery, which focuses on decentralization of services, task shifting and community involvement will be discussed. To improve the health care worker shortage in sub-Saharan Africa, the conventional model of health care delivery must be replaced with an innovative model that utilizes doctors, nurses and community members more effectively.

Key Words: Antiretroviral therapy; Health care workers; HIVIAIDS; SubSaharan Africa; United Nations millennium development goals

s of 2008, the number of individuals living with HIV was Aover 33,000,000 worldwide $(1,2)$. The HIV/AIDS epidemic continues to be a priority health issue on the global agenda, particularly in resource-poor settings and among vulnerable populations. The United Nations (UN) millennium development goals (MDGs) were enacted in 2000 and advocated for universal access to ART by 2010. At the end of 2008, there were approximately three million people accessing ART, well below the intended trajectory to meet the MDG. In addition, access to ART continues to be significantly worse in areas with the highest prevalence of AIDS (2). This MDG of universal access to ART will not be met by 2010, yet it is imperative that the momentum created by this global collaboration be maintained and that we continue working toward improving access to ART and strengthening health care systems.

There has been considerable effort spent on examining the challenges to providing universal access to HIV/AIDS treatment - the two most important challenges being the financial shortfalls and the shortage of health care workers. Many experts are now suggesting that the shortage of health care

\section{L'accès universel à l'antivirothérapie sera-t-il un jour possible? Le défi des travailleurs de la santé}

L'objectif du Millénaire pour le développement des Nations Unis prévoyant l'accès universel à l'antirétrovirothérapie (ART) d'ici 2010 pour les patients qui vivent avec le VIH-sida est impossible à réaliser. En ce moment, quatre millions de personnes reçoivent une ART, sur un nombre estimatif de 13,7 millions qui en ont besoin. Pour réaliser cet objectif, la pénurie de travailleurs de la santé dans les régions du monde à faible revenu et aux faibles ressources constitue un défi important. Les pays d'Afrique subsaharienne présentent $68 \%$ du fardeau mondial de la maladie découlant du sida, mais ne comptent que $3 \%$ des travailleurs de la santé du monde. Cette pénurie est principalement causée par "l'exode des cerveaux » national et international, la mauvaise répartition des travailleurs de la santé au sein des pays et leur épuisement professionnel.

Même si l'objectif du Millénaire pour le développement des Nations Unis prévoyant l'accès universel à l'ART ne sera pas atteint en 2010, il est capital de continuer de poursuivre sur la lancée suscitée par cet objectif humanitaire. Les auteurs ont rédigé la présente analyse bibliographique afin d'attirer l'attention des chercheurs et des politiques vers les données probantes tirées de projets à petite échelle en Afrique subsaharienne qui ont réussi à accroître l'accès à l'ART. Notamment, les auteurs exposent un modèle de prestation de l'ART de première ligne, axé sur la décentralisation des services, le transfert des tâches et la participation de la collectivité. Pour améliorer la pénurie de travailleurs de la santé en Afrique subsaharienne, il faut remplacer le modèle traditionnel de prestation des soins par un modèle novateur qui recourt avec plus d'efficacité aux médecins, aux infirmières et aux membres de la collectivité.

workers has surpassed funding insufficiencies as the primary limiting factor to combating HIV/AIDS $(3,4)$. The 46 countries in sub-Saharan Africa average 0.8 health care workers per 1000 people (2). It has been reported that to provide universal access to ART as well as current medical care for all illnesses, at least 2.5 health care workers per 1000 people would be required $(3,4)$. To increase the number of patients on ART, fundamental changes to health care systems and delivery models are necessary. The objective of the present paper is to shed light on the health care worker shortage with respect to scaling-up ART and to attract research and policy attention to the inadequate health care systems in sub-Saharan Africa.

\section{THE MDGS}

The MDGs were developed in September 2000 by the heads of state of 189 UN countries (5) (Table 1). The MDGs differ from previous humanitarian goals because they were created around a global partnership between developed and developing countries (5). Specifically, developed countries are involved through financial assistance, debt relief, fair trade and improved

\footnotetext{
${ }^{1}$ Department of Community Health $E \mathcal{G}$ Epidemiology; ${ }^{2}$ Division of Infectious Diseases, Dalhousie University, Halifax, Nova Scotia

Correspondence and reprints: Dr Walter F Schlech III, Division of Infectious Diseases, Dalhousie University, 5820 University Avenue, Halifax,

Nova Scotia B3H 1V7. Telephone 902-473-7742, e-mail Walter.Schlech@dal.ca
} 


\begin{tabular}{|c|c|}
\hline Goal & Target \\
\hline 1. To eradicate extreme hunger and poverty & Halve the proportion of people whose income is less than $\$ 1$ per day by 2015 \\
\hline 2. To achieve universal primary education & Ensure that by 2015 , all children are able to complete primary schooling \\
\hline 3. To promote sex equality and empower women & Eliminate sex disparity in education by 2015 \\
\hline 4. To reduce child mortality & Reduce the under-five mortality rate by two-thirds by 2015 \\
\hline 5. To improve maternal health & Reduce the maternal mortality ratio by three-quarters by 2015 \\
\hline \multirow[t]{3}{*}{ 6. To combat HIVIAIDS, malaria and other diseases } & Target 1: To stop and begin reversing the spread of HIVIAIDS by 2015 \\
\hline & Target 2: To have universal access to HIVIAIDS treatment to all who need it by 2010 \\
\hline & Target 3: To stop and begin reversing the spread of malaria and other major diseases \\
\hline \multirow[t]{4}{*}{ 7. To ensure environmental sustainability } & $\begin{array}{l}\text { Target 1: Integrate the principles of sustainable development into policies and programs, } \\
\text { and reverse the loss of environmental resources }\end{array}$ \\
\hline & Target 2: Achieve a significant reduction in biodiversity rate loss by 2010 \\
\hline & $\begin{array}{l}\text { Target 3: Halve the proportion of the global population without sustainable access to safe } \\
\text { drinking water and basic sanitation by } 2015\end{array}$ \\
\hline & Target 4: Improve the lives of at least 100 million slum dwellers by 2020. \\
\hline \multirow[t]{3}{*}{ 8. To develop a global partnership for development } & Target 1: Deal comprehensively with debt of developing countries \\
\hline & Target 2: Assist in providing access to affordable, essential drugs in developing countries \\
\hline & Target 3: Make new technologies available \\
\hline
\end{tabular}

Adapted from reference 6

provision of pharmaceuticals (5). This agreement from all UN countries has attracted immense attention and created momentum for implementing the eight goals; unfortunately, the outlook after nine years is bleak for most of the MDGs.

Overall, significant progress has been made for all eight goals; however, the most troubled and impoverished areas of the world are lagging far behind (6). The number of people living on less than $\$ 1$ per day has decreased steadily, 1.6 billion people have gained access to safe drinking water since 1990 and the number of people infected with AIDS fell by $10 \%$ between 2001 and 2007 (6). However, when these targets are examined more closely, it can be seen that as of $2008,51.4 \%$ of people in sub-Saharan Africa still lived on less than $\$ 1$ a day, there were 2.5 billion people who still did not have safe drinking water and only $31 \%$ of people in sub-Saharan Africa who required HIV/AIDS treatment were receiving it $(6,7)$. Although the outlook for the MDGs is not promising, the eight benchmarks have allowed for evaluation and accountability for all countries. One can only hope that the attention and momentum created from the MDGs can outlive the 2015 deadline, and that the international community will continue to work together to reach the end points agreed on.

The remainder of the present paper will focus on the sixth MDG, specifically, the effort to combat HIV/AIDS; however, the challenges to accomplishing this goal are not isolated from the other seven MDGs. Implementation of all eight goals requires immediate and sustained support through financial assistance and human resource advancement.

\section{HEALTH CARE WORKER SHORTAGE}

Description of the shortage in sub-Saharan Africa It is argued by some that there is not a global pandemic of HIV/ AIDS, but two multinational epidemics $(2,8)$. The one epidemic has much lower prevalence, is spread throughout the world and is roughly contained within high-risk populations (ie, homosexual men, intravenous drug users and commercial sex workers), while the second epidemic is focused in sub-Saharan Africa but has a much higher prevalence in the general population (2). The adult prevalence of HIV/AIDS in sub-Saharan
Africa was $5 \%$ in 2007, compared with the global adult prevalence of approximately $0.8 \%$ (2). The two epidemics of HIV/ AIDS are not mutually exclusive; however, they have fundamental differences and cannot be dealt with using identical strategies. Moreover, within each of the two large-scale epidemics, the demographics and risk factors are not homogenous (8). The disease characteristics and progression, primary route of transmission, as well as social and cultural determinants of HIV/AIDS differ between and within countries. Therefore, implementation of prevention or treatment programs should take into consideration and take advantage of the specific disease and cultural characteristics in each area.

The lack of nurses, doctors and other health care providers in sub-Saharan Africa is a significant barrier to effective health care systems. It has been estimated that this area bears $24 \%$ of the world's burden of illness from all diseases, yet has only $3 \%$ of the health care workers and $1 \%$ of the financial resources for health care worldwide (9). For example, in rural Malawi and all of Lesotho, $60 \%$ and $54 \%$ of nursing positions are vacant (3). To care for the burden of disease in sub-Saharan Africa, millions of additional health care workers will be required (4). It has been reported that for countries in sub-Saharan Africa to meet the sixth MDG, they would require 2.5 health care workers for 1000 people (3). Only six of the 46 sub-Saharan African countries fulfill this estimate, with the overall average being 0.8 health care workers per 1000 people (10). To put this value into context, North America has 9.9 health care workers per 1000 people (10).

There is evidence that the number of health care workers is positively correlated with the quality of care and access to care (11). The health care worker shortage is very complex and includes social, political and psychological contributions. The principle factors surrounding human health resources in subSaharan Africa are an insufficient number of health care workers in sub-Saharan Africa, maldistribution of workers within countries and low productivity of health care workers (9). These three primary factors affect all of the health MDGs, but are of the utmost importance when we attempt to increase access to ART. 


\section{Insufficient number of workers}

There is little debate that the countries in sub-Saharan Africa require more health care workers; however, the reasons behind the shortage are less well known. In 2007, the World Health Organization (WHO) estimated that 20 doctors and 100 nurses were required to adequately care for a population of 100,000 (12). At this time, Malawi had two doctors and 63 nurses, and Mozambique had three doctors and 20 nurses per 100,000 people. (12) In comparison, the United States had 247 doctors and 901 nurses, and the United Kingdom had 222 doctors and 1170 nurses (12). The insufficient number of health care workers in sub-Saharan Africa is highly influenced by workers emigrating from their native countries, insufficient training facilities and loss of workers due to illness. The 'brain drain' of health care workers from countries in sub-Saharan Africa is the most wellknown and highly publicized cause of the health care worker crisis. Eight per cent of doctors trained in Lusaka, Zambia, in the 1980s stayed in 1999, and only 30\% of Zimbabwean doctors trained in the 1990s were still in the country in 2001 (4). Doctors, nurses, pharmacists and laboratory technicians are emigrating because of low wages, poor working and living conditions, and inadequate government support; those who stay are relied on to work longer hours and in more stressful and desolate conditions $(12,13)$. Even the most committed and altruistic workers quickly lose hope and are drawn to improved living and working conditions.

In addition to the 'brain drain,' there are inadequate numbers of health care workers because of insufficient medical and nursing education programs in sub-Saharan Africa. Eleven of the 46 sub-Saharan African countries have no medical schools, and 30 have only one medical school (9). Therefore, the majority of sub-Saharan African doctors are trained outside of their home countries, thereby decreasing the chance that they will return and practice at home. Due to the lack of financial and human resources in many sub-Saharan African countries, it is very difficult to increase education opportunities.

\section{Poor distribution of health care workers}

Throughout sub-Saharan Africa, there is a skewed distribution of doctors and nurses. In many countries of sub-Saharan Africa, the number of health care workers in urban cities is significantly greater than in rural communities (9). Health care workers are often drawn to urban settings for similar reasons as those who are drawn abroad: better wages, improved working conditions and greater opportunity for advancement. However, the burden of HIV/AIDS is often much higher in rural areas because access to services is worse (12). Additionally, health care workers are drawn to private clinics and nongovernmental organizations, leaving a small proportion of workers to care for the majority of the population (13).

HIV/AIDS is not only adding to the burden of disease in sub-Saharan Africa, it is changing the distribution of care. Due to the prevalence of HIV/AIDS in this area and the complexity of therapy, care for individuals living with HIV/AIDS is taking up an enormous proportion of health care services and nurse and physician time, often to the neglect of other diseases (14). This has caused an increased need for long-term and chronic care providers, as well as more attention on public health, yet the health care system and the distribution of health care providers have not responded. Therefore, we are attempting to apply a conventional health care delivery model to a nonconventional health care problem. This has resulted in inefficient physician and nurse utilization, as well as immense shortages of health care workers who specialize in infectious disease. The WHO and Médicins Sans Frontières have now developed delivery models that rely much more heavily on task shifting of duties and decentralization of care $(15,16)$. However, these models are slow to be implemented because they require a shift in health systems and medical education in these countries. Innovative delivery models are often opposed by health care workers, medical and nursing associations, and policy makers, due to fear of significant change and protectionism within traditional health care roles (4).

\section{Health care worker productivity and disease burden}

Health care workers throughout sub-Saharan Africa should be praised for their courage and commitment to the health of their community. They work in overcrowded and understaffed clinics, with very little opportunity for advancement, and in fear of contracting HIV - and do it all for minimal salaries (16). These working conditions often take their toll on health care workers, causing low productivity and burnout. As outlined above, the poor working conditions often heavily influence the decision of health care workers to leave the country; it also causes psychological and physical harm for those who stay. They experience suffering and death countless times a day and are often caring for terminally ill relatives outside of work. To compound these effects, nurses and physicians rarely have an opportunity to discuss the suffering they observe and experience due to the stigma surrounding HIV/AIDS (17). The stigmatization of AIDS prevents communication, thereby resulting in workers keeping these experiences to themselves and not allowing them to adequately cope. After a period of time, the physical and psychological stress has been shown to result in increased absenteeism, reduced enthusiasm and commitment, as well as worse quality of care for patients (17). To improve efficiency and retention of workers, there must be improved community and social support and improved working environments for health care workers.

The health care worker situation in sub-Saharan Africa is a complex and multifaceted issue. It cannot be completely remedied in the immediate future, but also cannot be ignored. Adding to the problem is the fact that funding agencies and governments have concentrated insufficient money and academic attention on health care worker issues (3). This crisis has been overshadowed by research and funding to advance medical technologies; however, research on efficacy and efficiency of health care providers must run parallel with biomedical research or any improvement will not be possible (18).

\section{WHAT CAN BE DONE NOW AND IN THE FUTURE?}

The health care worker shortfalls in sub-Saharan Africa are dire. However, many countries have ambitious programs to increase ART access by 10 to 20 times (4). There is no clearcut formula for solving these issues; but, there has been notable progress in different areas throughout sub-Saharan Africa. Several small-scale projects have focused on decentralization, task shifting and community involvement and should be used as blueprints for nationwide implementation. 
The conventional model of health care delivery is not optimal for the current health care situation in many countries in sub-Saharan Africa. To treat more patients and more effectively utilize health care worker services, the WHO and Médicins Sans Frontières are calling for a primary-care approach with greater community involvement $(12,19)$. This includes moving HIV/ AIDS services out of centrally located hospitals, delegating care to lesser-trained workers and stimulating collaboration and involvement from community members. If these strategies are put into action in parallel with increased national government support and international assistance, significant change is possible in the short and long term. Due to the differences in disease characteristics of HIV/AIDS in each country, it is important to emphasize catering intervention strategies to each area.

Presently, HIV/AIDS services in sub-Saharan Africa are administered primarily by doctors in centrally located hospitals. The care for HIV/AIDS is delivered using a conventional model of health care delivery, with doctors being responsible for diagnosing, prescribing and providing services. Nurses assist doctors by monitoring patients and administering medication. Additionally, care is provided mostly in urban hospitals with little community involvement (16). The battle against HIV/AIDS cannot be left to nurses and doctors in urban cities. There must be community involvement and support, as well as a more efficient approach to providing HIV/AIDS services in all areas.

\section{Decentralization and simplification}

First and foremost, ART must be decentralized throughout communities. This would increase accessibility to services and stimulate community involvement and support (16). Decentralization has been successful in small-scale pilot projects, in which clinics are organized and run by community members (16). Lay people are trained to assist nurses in preparation of ART and to provide information to patients and families. Medically trained community members are also a fundamental component of homebased HIV/AIDS care, in which patients are monitored within their community (20). Trained lay people also play a significant role in decreasing stigma about HIV/AIDS and act as a liaison between the community and health care workers. A decentralized model of HIV/AIDS care was shown to increase long-term adherence to ART regimens and maintain quality of care (21). Community-based clinics have been successful in small-scale projects in rural, remote and low-resource areas of low-income countries $(16,22)$.

In addition to making HIV/AIDS care more community centred, there is emerging research that calls for simplification of ART monitoring (23). Providing ART in rural and remote areas is challenged because of the continuous monitoring of AIDS patients through clinical and laboratory testing. A recent study (23) from the Development of Antiretroviral Therapy (DART) in Africa trial compared patient outcomes from a group that received ongoing laboratory (12-weekly CD4 counts) and clinical monitoring with a group that received only clinical monitoring. The study reported that routine laboratory monitoring did not influence the likelihood of adverse events or substitutions in first-line ART for the first two years after initiation of treatment (23). The impact of monitoring became significant to patient outcomes after two years. More research is needed to validate these results before putting them into practice. However, through simplification of patient monitoring, there is the potential to further decentralize ART and improve access in difficult-to-reach areas.

Decentralizing ART services away from urban hospitals, not only improves accessibility for rural areas and creates community support, it also relieves the hospital bottleneck (24). Providing ART in rural clinics speeds up the initiation process, allows more people to receive care and frees up hospitals for other services (24). ART clinics can be quite basic and can be run primarily by community members and nurses (24). In this decentralized approach, doctors play a more supervisory role, and delegate many of the tasks to nurses and medically trained community members.

Although decentralization of health care services in lowincome countries has been shown to be effective in increasing ART delivery, it is not a complete solution in and of itself (25). Decentralization of ART must take place within an organized health care system and cannot be successful without committed national leaders. Moreover, to sustain high ART coverage through decentralization, ongoing training of personnel and evaluation of programs are required.

\section{Task shifting}

In addition to decentralizing HIV/AIDS care, delegating ART tasks to lower-cadre health care workers will contribute significantly to improving the shortage of workers (16). Because the main limiting factor of increasing ART access in sub-Saharan Africa is the number of available nurses and doctors, many have suggested that conventional health care roles be modified (19). The services involved in ART are repetitive and relatively simple to administer, yet labour intensive (26). If community members were trained to conduct some of the less technical and complex services, and nurses were given greater autonomy to administer and prescribe ART, then more patients could be cared for, in comparison with a doctor-driven delivery model (12). Current taskshifting models vary by the level of education that is provided and the clinical skills that are taught to community members. These medically trained community members also vary by their title (adherence counsellors, clinical officers or medical assistants), their tasks and the program location (27).

A task-shifting model was applied in Lusikisiki, South Africa, which is a rural and resource-poor area with 14 times fewer doctors than the national average (16). In this program, adherence counsellors were responsible for registering patients, preparing ART, and providing support and information for patients and families. Nurses had a much more active role in prescribing and administering therapy and monitoring patients. Doctors travelled to many different clinics and supervised the operations and dealt with complex and severely ill patients (16). This form of task-shifting model enabled Lusikisiki to reach a greater number of patients throughout the area (16).

A task-shifting model is beneficial to improve access, but must be balanced with quality of care. Reports from small-scale projects have demonstrated similar quality of care and superior patient outcomes when compared with traditional models (21). This community-centred and bottom-up strategy is possible in low-income countries and in low-resource areas (16). It is an approach that does not require significant policy or infrastructural changes or financial support, yet would require health care workers and administrators to be on board. Countries would need to invest in setting up or modifying clinics and training and employing community members as counsellors. 
The strategy outlined above is focused around improving efficiency of health care systems and workers, as well as developing inexpensive and applicable changes. To compliment these changes, the countries in sub-Saharan Africa require additional funding to sustain the new capacity and strengthen national health care. Training more African health care workers will be a slow and costly venture, but one that will significantly improve long-term health and well being of African populations. Increasing the number of newly trained community members, nurses and doctors will relieve pressure on the present workers, improve working conditions and rebuild confidence in national health care systems.

The financial, government and research attention focused on HIV/AIDS services is often criticized for being at the expense of other global diseases and health system challenges. Although HIV/AIDS does receive significant attention, the benefit has spread into other aspects of health care systems. HIV/AIDS services have contributed to increasing infrastructure through financial assistance, have shed light on present fragilities in health systems worldwide and have increased global and national urgency for health system strengthening (28). The HIV/AIDS epidemic does not act independently from other diseases or global challenges; therefore, we must continue to work toward increasing capacity and strengthening health care systems while striving for prevention and treatment.

\section{CONCLUSION}

The chance of providing universal access to ART by 2010 has come and gone. There are simply too few health care workers and too much need in many areas of the world. This is a result of a national and international 'brain drain,' difficult working conditions and inefficient health care systems. However, through all the despair and negativity, there have been rays of hope. The MDGs have fostered unprecedented agreement, growing international collaboration, and media and government attention. There have been several successful small-scale projects in South Africa, Malawi and Uganda, which have been able to improve conditions and increase access to HIV/ AIDS services. We must learn from these projects and continue to move forward beyond 2010.

HIV/AIDS affects almost everyone in some capacity worldwide. We can no longer allow the battle against the epidemic to be fought by a select number of health care workers, researchers and government officials. Community involvement and support is imperative in making changes and providing adequate care. In parallel, we must stop trying to deal with HIV/AIDS using conventional models of health care delivery. We must put bureaucracy and tradition aside and promote delegation and decentralization, increase the number of health care workers, and fund sustainable wage increases for health care workers. Complacency is unacceptable, and the developed world needs to be re-energized to meet the challenge.

ACKNOWLEDGEMENT: The authors are very grateful for the support and assistance from Shawna O'Hearn and the International Health office at Dalhousie University, Halifax, Nova Scotia.

\section{REFERENCES}

1. UNAIDS. Universal access to HIV treatment, prevention, care, and support. <www.unaids.org/en/CountryResponses/UniversalAccess/ default.asp $>$ (Version current at October 28, 2009).

2. UNAIDS. World Health Organization. AIDS epidemic update. <data.unaids.org/pub/EPISlides/2007/2007_epiupdate_en.pdf> (Version current at August 27, 2009).

3. Chen L, Evans T, Anand S, et al. Human resources for health: Overcoming the crisis. Lancet 2004;364:1984-90.

4. Van Damme W, Kober K, Kegels G. Scaling-up antiretroviral treatment in Southern African countries with human resource shortage: How will health systems adapt? Soc Sci Med 2008;66:2108-21.

5. Haines A, Cassels A. Can the millennium development goals be attained? BMJ 2004;329:394-7.

6. United Nations. The millennium development goals report 2008. $<$ www.un.org/millenniumgoals/pdf/The $\% 20$ Millennium $\% 20$ Development\%20Goals\%20Report\%202008.pdf> (Version current at August 27, 2009).

7. McCoy D, Chopra M, Loewenson R, et al. Expanding access to antiretroviral therapy in sub-Saharan Africa: Avoiding the pitfalls and dangers, capitalizing on the opportunities. Am J Public Health 2005;95:18-22.

8. Piot P, Bartos M, Ghys P, Walker N, Schwartlander B. The global impact of HIV/AIDS. Nature 2001;410:968-73.

9. Anyangwe S, Mtonga C. Inequities in the global health workforce: The greatest impediment to health in sub-Saharan Africa. Int J Environ Res Public Health 2007;4:93-100.

10. World Health Organization. Addressing Africa's health workforce crisis: An avenue for action. <www.hlfhealthmdgs.org/Documents/ AfricasWorkforce-Final.pdf> (Version current at August 27, 2009).

11. World Health Organization. Working together for health. <www.who.int/whr/2006/whr06_en.pdf> (Version current at August 27, 2009).

12. Médicins Sans Frontières. Help wanted: Confronting the health care worker crisis to expand access to HIV/AIDS treatment: MSF experience in Southern Africa. <www.msf.org/source/countries/

africa/southafrica/2007/Help_wanted.pdf> (Version current at August 27, 2009).

13. Kober K, Van Damme W. Scaling up access to antiretroviral treatment in Southern Africa: Who will do the job? Lancet 2004;364:103-7.

14. Hagopian A, Micek M, Vio F, Gimbel-Sherr K, Montoya P. What if we decided to take care of everyone who needed treatment? Workforce planning in Mozambique using simulation of demand for HIV/AIDS care. Hum Resour Health 2008;6:3.

15. World Health Organization. Chronic HIV care with ARV therapy and prevention. <www.who.int/3by5/publications/documents/en/ IMAI_chronic.pdf $>$ (Version current at August 27, 2009).

16. Medicins Sans Frontier. Achieving and sustaining universal access to antiretrovirals in rural areas: The primary health care approach to HIV services in Lusikisiki, Eastern Cape. <fieldresearch.msf.org/ msf/bitstream/10144/49421/1/Case\%20Lusilisiki\%202006.pdf> (Version current at August 27, 2009).

17. Dieleman M, Biemba G, Mphuka S, Sichinga-Sichali K, Sissolak D, Kwaak A. 'We are also dying like any other people, we are also people': Perceptions of the impact of HIV/AIDS on health workers in two districts in Zambia. Health Policy Plan 2007;22:139-48.

18. 2009 International AIDS Society Conference. Learning by doing? Operations research to strengthen HIV, prevention, care and treatment scale-up in resource limited settings: What, why, and how? <www.ias2009.org/subpage. aspx?pageld =400> (Version current at October 28, 2009).

19. World Health Organization. Integrated management of adolescent and adult illness. <www.who.int/3by5/publications/documents/imai/en/> (Version current at August 27, 2009).

20. Ncama BP. Models of community/home-based care for people living with HIV/AIDS in Southern Africa. J Assoc Nurses AIDS Care 2005; 16:33-40.

21. Zachariah R, Teck R, Buhendwa L, et al. Community support is associated with better antiretroviral treatment outcomes in a resource-limited rural district in Malawi. T Roy Soc Trop Med H 2007;101:79-84. 
22. Zachariah R, Teck R, Buhendwa L, et al. How can the community contribute in the fight against HIV/AIDS and tuberculosis? An example from a rural district in Malawi. T Roy Soc Trop Med H 2006;100:167-75

23. Mugyenyi P, Walker S, Hakim J, et al. Impact of routine laboratory monitoring over 5 years after antiretroviral therapy (ART) initiation on clinical disease progression of HIV-infected African adults: The DART trial final results. 2009 International AIDS Society Conference. <www.ias2009.org/pag/Abstracts. aspx?AID=3807> (Version current at January 26, 2009).

24. Ford N, Reuter Her, Bedelu M, Schneider H, Reuter Hel. Sustainability of long-term treatment in a rural district: The Lusikisiki model of decentralized HIV/AIDS care. S Afr Med J 2006;25:17-20.
25. Loubiere S, Boyer S, Protopopescu C, et al. Decentralization of HIV care in Cameroon: Increased access to antiretroviral treatment and associated persistent barriers. Health Policy 2009;92:165-73.

26. Makombe S, Jahn A, Tweya H, et al. A national survey of the impact of rapid scale-up of antiretroviral therapy on health-care workers in Malawi: Effects on human resources and survival. Bull World Health Organ 2007;85:851-7.

27. Dovlo D. Using mid-level cadres as substitutes for internationally mobile health professionals in Africa. A desk review. Hum Resour Health 2004;2:7.

28. The International Treatment Preparedness Coalition. The HIV/ AIDS response and health systems: Building on success to achieve healthcare for all. <www.itpcglobal.org/images/stories/doc/Missing the_Target_6.pdf> (Version current at October 28, 2009). 


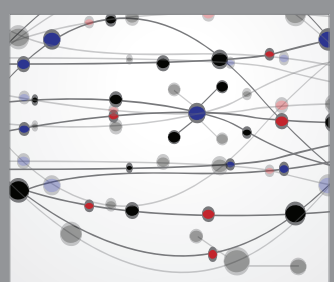

The Scientific World Journal
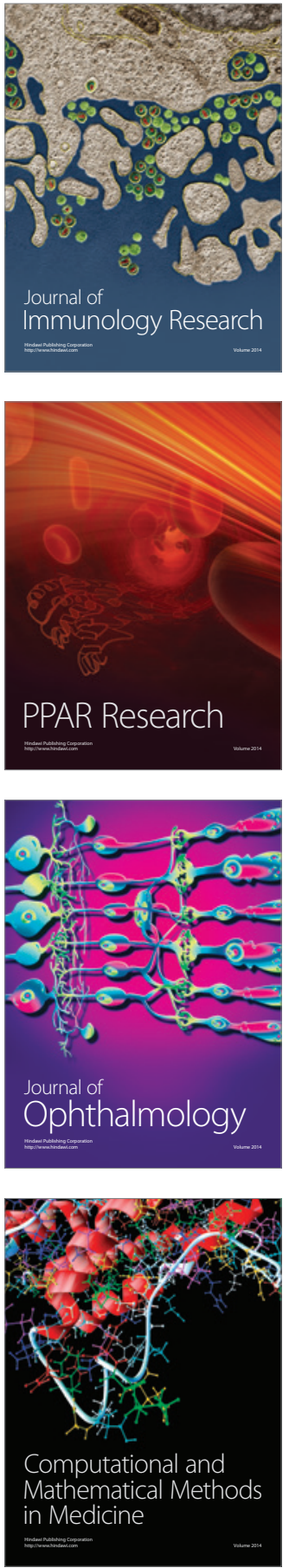

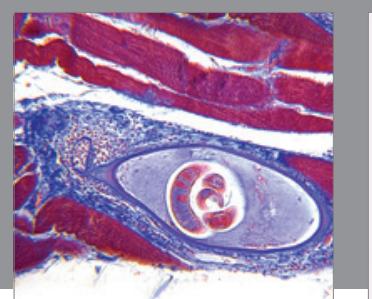

Gastroenterology Research and Practice

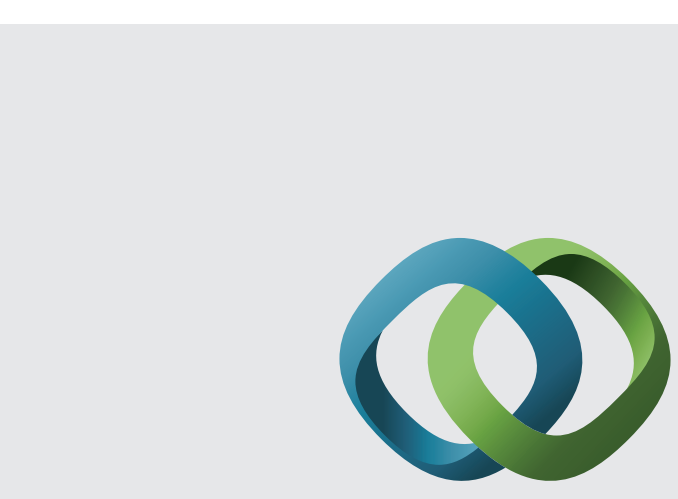

\section{Hindawi}

Submit your manuscripts at

http://www.hindawi.com
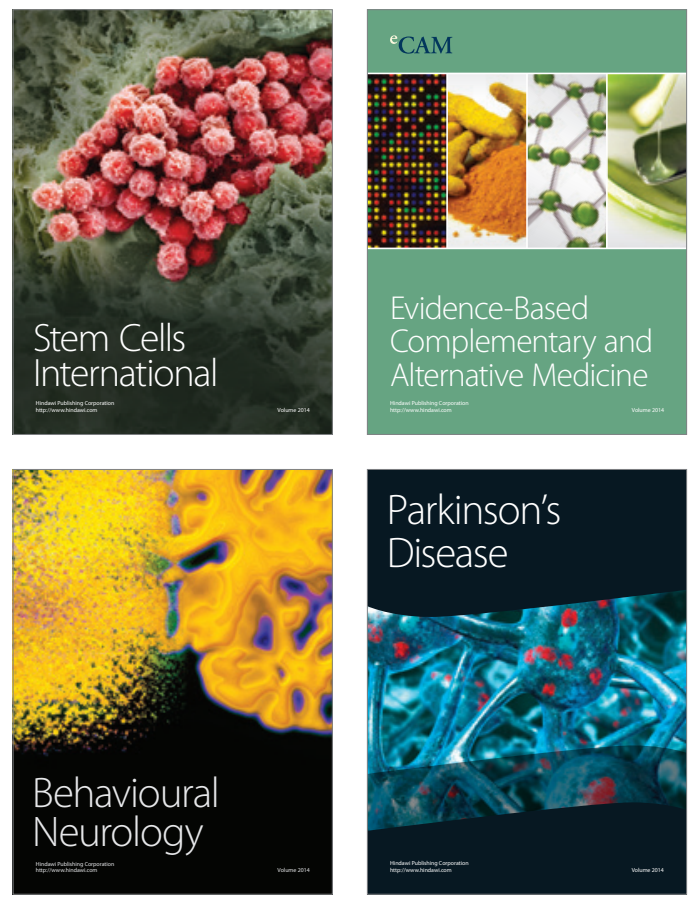
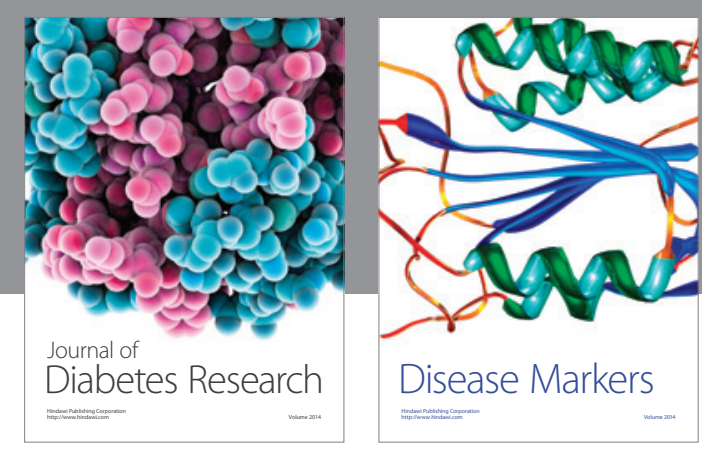

Disease Markers
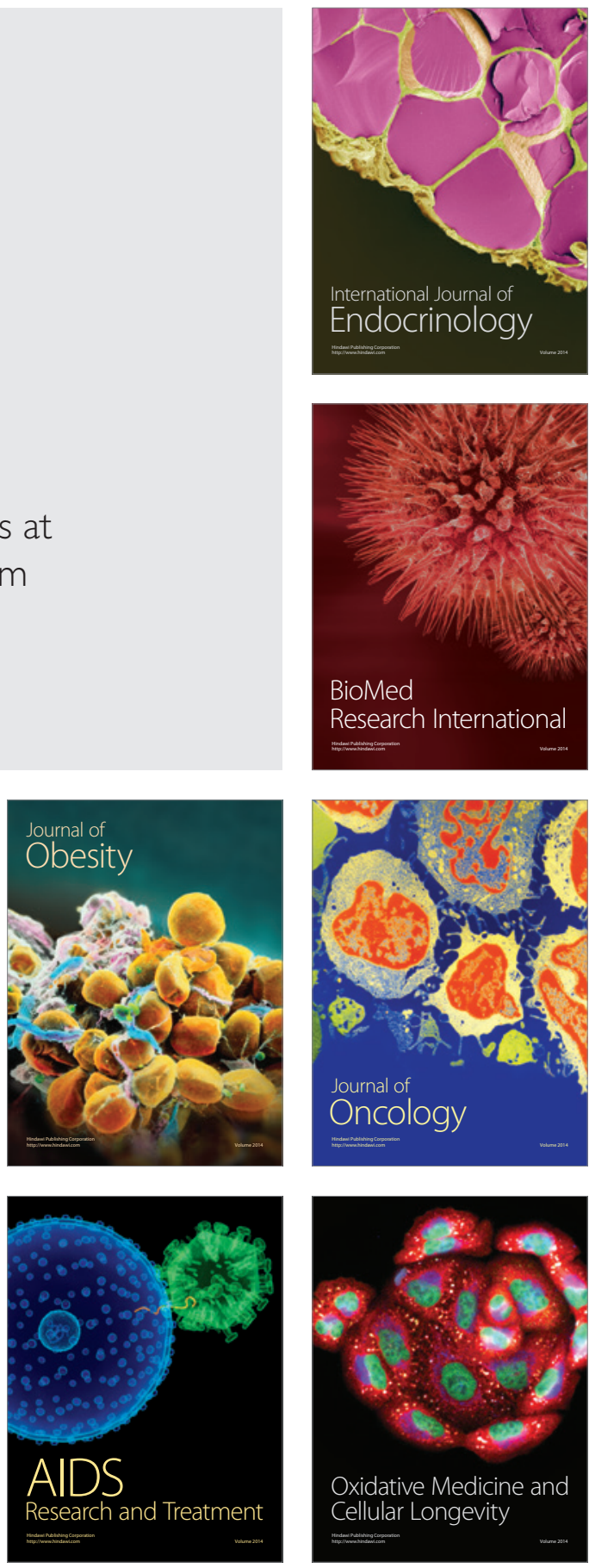